\title{
The fourth dimension
}

\author{
Robert B. Hawkins, MD, MSc
}

From the Division of Thoracic and Cardiovascular Surgery, Department of Surgery, University of Virginia, Charlottesville, Va.

Disclosures: Author has nothing to disclose with regard to commercial support.

Received for publication July 12, 2018; accepted for publication July 13, 2018; available ahead of print Aug 11, 2018.

Address for reprints: Robert B. Hawkins, MD, MSc, Division of Thoracic and Cardiovascular Surgery, Department of Surgery, University of Virginia, PO Box 800679, Charlottesville, VA 22908 (E-mail: RBH6X@ virginia.edu).

J Thorac Cardiovasc Surg 2019;157:492-3

0022-5223/\$36.00

Copyright $(2) 2018$ by The American Association for Thoracic Surgery

https://doi.org/10.1016/j.jtcvs.2018.07.021

In this issue of the Journal, Burris and colleagues ${ }^{1}$ present a brief research report examining the potential association between regurgitant flow within the false lumen of a descending thoracic aortic aneurysm on 4-dimensional (4D) magnetic resonance imaging (MRI) and progressive enlargement over time. Although medical management of uncomplicated type B aortic dissection is the gold standard in care, patient surveillance and close follow-up is warranted, as approximately one half will have aneurysmal growth of their dissection. ${ }^{2}$ The monetary cost of repeat imaging and clinic visits as well as the clinical costs of potential end-organ dysfunction, catastrophic rupture, or emergent interventions are not insignificant. Therefore, investigators are focused on identifying both the pathophysiologic causes of progressive enlargement as well as predictors that can be used to identify patients who need increased surveillance or potentially early prophylactic intervention.

Variable risk factors for aneurysm formation have been identified, with anatomic characteristics including a patent or large false lumen as well as large or singular entry tear. ${ }^{3}$ It is the combination of these anatomic characteristics that leads to the hemodynamics that pressurize the false lumen and cause dilatation. Although static imaging can identify some of these risk factors, it makes far more sense to measure the flow dynamics of the dissection. This requires 4D imaging to noninvasively measure, something that is underused in medicine. The fourth dimension of time was popularized by Charles Hinton in 1886, when he coined the term tesseract to display the 4D equivalent of a 3-dimensional cube. ${ }^{4}$ Working on his theory of special relativity, Einstein proved the interdependence of the 4 dimensions, now known as the space-time continuum. Many cardiovascular pathologies are uniquely timedependent due to the beating heart and variation in blood pressure. However, time-resolved diagnostics are only a recent phenomenon. MRI over the past few decades has

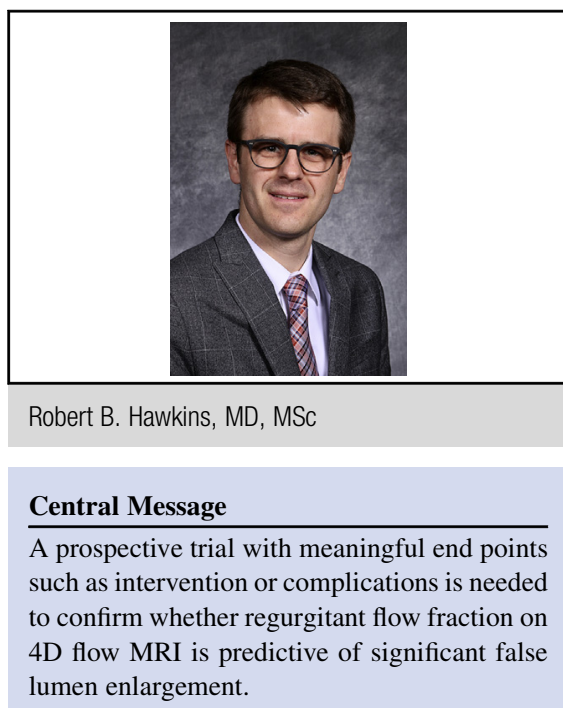

See Article page 488

progressed from static 2-dimensional planar cuts with the addition of 3-dimensional reconstructions, phase contrast MRI measuring velocities, and time-resolved (Cine) series. ${ }^{6}$ The combination of these technologies gives us beautiful 4D flow imaging with a plethora of data. The downsides of such advanced imaging include cost, long scan times, motion artifact, and timeintensive postprocessing. ${ }^{7}$

The application of 4D flow imaging is perfect for aortic disease and in particular dissections. Although modeling the flow dynamics of the entire dissected aorta may be theoretically be possible for some patients, the authors have chosen to measure a surrogate marker for pressurization. The logic appears sound in that the regurgitant fraction will be inversely proportional to the outflow at distal tears and the regurgitant fraction is far easier and faster to estimate. Questions remain as to whether this simple metric can account for the often-complex anatomy. Only a larger, prospective trial will find the truth, the design of which can be difficult in the aortic population. The rapidity of aneurysm formation is variable, and some patients will require years-long follow-up with time-based statistical methods for analyzing results. In addition, multiple meaningful end points can be considered, such as descending aortic repair, organ dysfunction, cost, and more. The authors are to be congratulated on their hypothesis-generating study, and we look forward to seeing the results of a potential prospective study. 


\section{References}

1. Burris NS, Patel HJ, Hope MD. Retrograde flow in the false lumen: marker of a false lumen under stress? J Thorac Cardiovasc Surg. 2019;157:488-91.

2. Durham CA, Aranson NJ, Ergul EA, Wang LJ, Patel VI, Cambria RP, et al. Aneurysmal degeneration of the thoracoabdominal aorta after medical management of type B aortic dissections. J Vasc Surg. 2015; 62:900-6.

3. Schwartz SI, Durham C, Clouse WD, Patel VI, Lancaster RT, Cambria RP, et al. Predictors of late aortic intervention in patients

with medically treated type B aortic dissection. J Vasc Surg. 2018; 67:78-84.

4. Hinton CH. Scientific Romances: What Is the Fourth Dimension? London: S Sonnenschein \& Co, Ltd; 1886.

5. Einstein A. On the electrodynamics of moving bodies. Annalen der Physik. 1905; 10:891-921.

6. Stankovic Z, Allen BD, Garcia J, Jarvis KB, Markl M. 4D flow imaging with MRI Cardiovasc Diagn Ther. 2014;4:173-92.

7. Burris NS, Hope MD. 4D flow MRI applications for aortic disease. Magn Reson Imaging Clin N Am. 2015;23:15-23. 